Archived version from NCDOCKS Institutional Repository http://libres.uncg.edu/ir/asu/

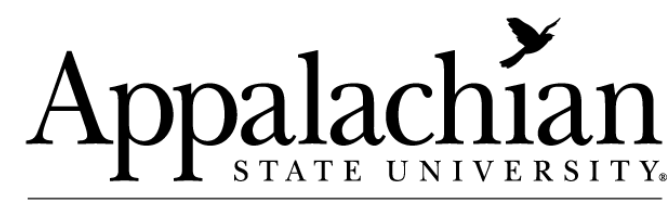

B O O N E, NORT H C A R O L I A

\section{DART Scale Development: Diagnosing A Firm's Readiness For Strategic Value Co-Creation}

\author{
By: Pia A. Albinsson, Yasanthi B. Perera, and Pookie Truly Sautter
}

\begin{abstract}
Value co-creation (VCC) requires firms to shift their operations from firm-centric, closed systems to more collaborative environments dedicated to the creation of reciprocal value for their network of value partners and consumer communities. This article presents the development of the DART scale that measures dimensions of Dialogue, Access, Risk assessment, and Transparency in customer interactions within the service experience environment. Evaluating the four dimensions allows firms to assess their institutional readiness for strategic value co-creation and encourages firms to reflect upon their use of structures and policies that support a climate conducive to strategic value co-creation.
\end{abstract}

Albinsson, P. A., Perera, B. Y., \& Sautter, P. T. (2016). DART SCALE DEVELOPMENT: DIAGNOSING A FIRM'S READINESS FOR STRATEGIC VALUE CO-CREATION. Journal of Marketing Theory and Practice, 24(1), 42-58. doi:http://dx.doi.org/10.1080/10696679.2016.1089763. Publisher version of record available at: https://www.tandfonline.com/doi/full/10.1080/10696679.2016.1089763 


\title{
DART SCALE DEVELOPMENT: DIAGNOSING A FIRM'S READINESS FOR STRATEGIC VALUE CO-CREATION
}

\author{
Pia A. Albinsson, B. Yasanthi Perera, and Pookie Truly Sautter
}

\begin{abstract}
Value co-creation (VCC) requires firms to shift their operations from firm-centric, closed systems to more collaborative environments dedicated to the creation of reciprocal value for their network of value partners and consumer communities. This article presents the development of the DART scale that measures dimensions of Dialogue, Access, Risk assessment, and Transparency in customer interactions within the service experience environment. Evaluating the four dimensions allows firms to assess their institutional readiness for strategic value co-creation and encourages firms to reflect upon their use of structures and policies that support a climate conducive to strategic value co-creation.
\end{abstract}

The service dominant logic of emergent literature indicates a significant shift in perspective regarding strategic value creation, what it entails, and who participates in the process. Prahalad and Ramaswamy (2004a, p. 5) argue that the conceptual understanding of value and the value creation process has shifted "from a productand firm-centric view to personalized customer experiences... [where] the interaction between the firm and the consumer is becoming the locus of value creation and value extraction." The nexus of value creation thus shifts from the corporation as the critical entity, which imbues product/service offerings with value, to the customer as a collaborator that interacts with the firm to create reciprocal value for all participants. This requires that, within the organizational structure, "[A] preparedness to use customer feedback must exist, and an effective internal support system is required, which manages to process the input and turn it into actionable information" (Grönroos 2012, p. 1532). Evolving perspectives on value co-creation (VCC) expand the context of relevant interactions beyond the scope of

Pia A. Albinsson (Ph.D., New Mexico State University), Associate Professor of Marketing, Walker College of Business, Appalachian State University, Boone, NC, albinssonpa@appstate.edu.

B. Yasanthi Perera (Ph.D., New Mexico State University), Assistant Professor of Business Ethics, Goodman School of Business, Brock University, St. Catharines, ON, yperera@brocku.ca.

Pookie Truly Sautter (Ph.D., Florida State University), Professor Emerita of Marketing, New Mexico State University, Las Cruces, NM, esautter@nmsu.edu.

The authors would like to recognize Dr. G. David Shows for his support in preparing this article. the traditional service encounter to customer/partner interactions across the broader service experience environment. The DART scale developed in this research evaluates critical dimensions of the experience environment; it is intended as a diagnostic measure of a firm's environmental readiness to pursue strategic VCC strategies.

Engaging consumers in product and service development is not new. Firms have long relied on focus groups to gain insights for new product development as well as for marketing purposes (Bendapudi and Leone 2003). The difference in recent years is that firms engage with larger groups of consumers in a way that facilitates even greater opportunity for individualized extraction of value by each consumer. This approach to consumer engagement, often termed value coproduction, (e.g., Ramirez 1999) or VCC (e.g., Wikström 1996; Prahalad and Ramaswamy 2002, 2004a, 2004b), is posited as a potential form of competitive advantage. Lusch and Vargo (2006) assert that coproduction is nested within the concept of co-creation and that the latter occurs "at the intersection of the offerer and the customer over time" (p. 284). Thus, despite the fact that we reference coproduction, similar to Roser et al. (2009); Lusch and Vargo (2006); and Payne, Storbacka, and Frow (2008), we use the term co-creation to reference value being created and extracted through consumer engagement over time.

Examples illustrate the strategic value of partner/customer engagement. Threadless.com, a successful t-shirt manufacturer, invites customer inputs on graphic designs and uses its online community to vote and select the design options ultimately used in production 
(Hoyer et al. 2010). Similarly, the high-end motorcycle manufacturer Ducati uses it online community, called the "TechCafe," to facilitate consumer sharing of technical knowledge with one another and to gather their suggestions for improving the next generation of Ducati products (Sawhney, Verona, and Prandelli 2005). This heightened consumer involvement in developing "customized, competitively compelling value propositions" (Vargo and Lusch 2004, p. 5) within the network of consumer communities is aligned with the progressive evolution in business logic from a goods-dominant to a service-dominant perspective emphasizing "intangibility, exchange processes, and relationships" (Vargo and Lusch 2004, p. 2).

While direct provider-customer interactions during service encounters retain focal interest as units of analysis, researchers demonstrate a growing interest in more robustly conceptualizing the various spheres of influence and partner processes that contribute to VCC (Grönroos 2012; Grönroos and Voima 2013; Ramaswamy and Gouillart 2010; Ramaswamy 2011; Skaržauskaitė 2013). Researchers extend conceptualization of VCC processes to entail interactions beyond the direct communications involved in the service encounter, to include interactions with and between customers and diverse partners before, during, and after the point of service delivery. This greater temporal and spatial scope contributes to the conceptualization of "value-in-use" as a concept that is a more holistic and expansive understanding of provider/customer resource integration and one that emphasizes the relational rather than transactional nature of VCC (Grönroos and Voima 2013). Thus, emerging perspectives on VCC shift the emphasis from value-inexchange to value-in-use, and from service encounter to experience environment where strategic focus includes all "purposeful interactions between the consumer and a network of companies and consumer communities" (Prahalad and Ramaswamy 2003, p.14).

Many scales exist that focus on individual traits and behaviors manifested by participants as predispositions or procedural traits relevant to the service encounter (e.g., Chan, Yim, and Lam 2010; Sierra, Heiser, and McQuitty 2009; Vernette and Hamdi-Kidar 2013; Yi and Gong 2013; Yim, Chan, and Lam 2012). While such constructs are highly relevant in understanding how customer contributions can be appropriated to benefit service outcomes, these individual level measures emphasize service encounter processes rather than the broader experience environment of strategic VCC (Grönroos and Voima 2013; Payne, Storbacka, and Frow 2008; Ramaswamy and Ozcan 2013). Payne, Storbacka, and Frow (2008, p. 89) acknowledge this weakness in their call for research on "key measures of co-creation ... [that] can be organized into systems to monitor, track and improve performance." To that end, this research is grounded in the work of Prahalad and Ramaswamy (2002, 2004a, 2004b) and details the development of the diagnostic DART scale that evaluates characteristics of the experience environment that enhance VCC at a broader and more ubiquitous level. Specifically, the DART scale uses multi item measures to evaluate the dimensions of Dialogue, Access, Risk assessment, and Transparency, the fundamental building blocks essential to the establishment of an organizational climate that fosters VCC (Prahalad and Ramaswamy 2002, 2004a, 2004b). The scale provides input for management strategy through benchmarking a firm's readiness for strategic VCC and can complement the use of other scales intended to measure and study participant traits/behaviors relevant to co-creation processes.

\section{DIMENSIONS OF DART}

DART dimensions are conceptualized as essential descriptors of organizational systems that invite and support strategic customer/partner interactions over the life of the service relationship. The first dimension, dialogue, supplants the traditional unidirectional flow of information from the provider to the consumer, to the creation of shared meaning that "require[s] deep engagement, lively interactivity, empathetic understanding, and a willingness by both parties to act, especially when they're at odds," upon the information received (Prahalad and Ramaswamy 2002, p.10). But beyond a willingness to exchange, meaningful dialogue also requires that customers have immediate and timely access to persons and resources that can facilitate a more evocative exchange of information and ideas. Thus, access, the second component of the DART model, facilitates dialogue and requires firms to optimize when, where, and how consumers are provided with the opportunity to cocreate value with the provider. Rather than regarding consumers as outsiders to the value creation process, to the fullest extent afforded by legal and competitor considerations, firms must seek to 
facilitate customer access to processes and resources that are used to create and deliver their product or service offerings. This facilitates the meaningful participation of customers in the VCC process.

Risk assessment, the third DART component, acknowledges that open access and dialogue also holds consumers, as value cocreators, partly responsible for the outcomes of the value creation process. Effective risk assessment provides consumers complete and accurate information about costs and benefits of their contributions, thereby facilitating informed decisions regarding the risks associated with the co-creation of the value offering. Although more traditional productcentric firms likely consider such honest disclosure as a potential threat to healthy customer relations, truly strategic VCC requires firms to treat participants as honored and trusted partners that work toward a common goal of value optimization.

Transparency in operations and information exchange is the fourth and final component of the DART model. In strategic VCC, successful firms share information that previously may have been considered proprietary and/or strategically dangerous to reveal outside the internal environment of the firm. Information shared can be diverse (e.g., transaction fees, security operations, profit margins, product development details) and may, at first glance, seem counterproductive in gaining customer loyalty and marketplace advantage. For example, MAX, a Swedish hamburger restaurant, shares the carbon footprint information for each menu item in form of carbon dioxide emissions. In doing so, the company clearly informs the public that, relative to vegetarian alternatives, their meat offerings have significantly greater environmental impact. Nonetheless, this transparency demonstrates the integrity of the firm and its commitment to openness and yet leaves open the possibility for further value creation opportunities with supply chain stakeholders.

Clearly, the DART components are codependent conditions in creating an organizational climate conducive to strategic VCC. Dialogue is critical but meaningful, genuine exchange cannot occur in the absence of access or transparency. In turn, these latter two components call upon firms to share accurate information with the consumers and, by doing so, allow these individuals, or businesses in the business-to-business (B-2-B) context, to assess risks (risk assessment) associated with the firms' products and services.
While firms may seek to adopt VCC as a competitive strategy, they may, nonetheless, experience difficulty in managing and integrating a culture and infrastructure supportive of VCC across the value chain (Prahalad and Ramaswamy 2000). This difficulty may be especially true in the case of firms founded and designed within the traditional firm-centric paradigm. Thus, the DART scale is particularly useful for firms that seek to engage in VCC because they assess organizational readiness and support for consumer participation and VCC. This information is also useful in identifying where, and how, a firm should consider modifying its internal structures and systematic policies in order to engage strategically in VCC endeavors. The following section discusses the creation of the DART scale for use in diagnosing the system's support for VCC strategies.

\section{STUDY 1: THE DEVELOPMENT OF THE DART SCALE}

Because the DART scale intends to measure the readiness of the experience environment as a multifaceted construct involving four components, various procedures advocated in the literature (Gerbing and Anderson 1988; Churchill 1979; DeVellis 1991; Ping 2004) were used in developing and validating the multidimensional scale.

\section{Item Development}

In developing the items for each of the four dimensions of the DART scale, we followed guidelines provided by Churchill (1979), Gerbing and Anderson (1988), and DeVellis (2003). The three authors conducted a thorough literature review of the theoretical discussions of VCC as an organizational strategy, with particular focus on organizational characteristics critical to the success of VCC strategies, including literature on the DART model (Prahalad and Ramaswamy 2002, 2004, 2004a, 2004b). Based on our review and discussions among the authors, an initial pool of 50 questions was generated to capture the four components of dialogue, access, risk assessment, and transparency (see Toncar et al. 2006). In regards to initially generating a large pool of questions that is reduced during scale refinement, DeVellis (2003, p. 65-66) states "By using multiple and seemingly redundant items, the content that is 
common to the items will summate across items while their irrelevant idiosyncrasies will cancel out ... you want considerable more than you plan to include in the final scale." Churchill (1979) suggests that exploratory research, such as discussions with various individuals, is useful in creating measures that capture the specified domains. Therefore, we began assessing content validity and face validity of the items by administering the initial items to an upper-level marketing class. In this process, we discussed the phrasing and meaning of each item and asked the students to match the items with each of the four VCC dimensions. Five items were eliminated in this initial process. Next, prior to a qualitative analysis of the items for content validity by managers and other professionals across various industries, three experts (e.g., business administration faculty members) evaluated the items for further screening of content and face validity (Bearden, Money, and Nevins 2006). Four items were eliminated in this stage. Next, four industry professionals (e.g., managers as experts) (Churchill 1979; DeVellis 2003) from four different industries (mining, retailing, computing, and health care) rated each statement using the following scale: 1 = clearly representative, 2 = somewhat representative, or $3=$ not representative of the respective dimensions in relation to their particular industry. Similar to Bearden, Netemeyer, and Teel (1989); Tian and McKenzie (2001); and Zaichkowsky (1985), we retained items that were rated by all judges as being clearly representative of the components, as well as those items evaluated as being clearly representative by at least three of the four judges, provided that the fourth individual rated the same item as being somewhat representative. The inter-rater reliability for the ratings by the four judges was 83 percent (Stemler 2004). Based on this review process, we eliminated 4 additional items for a total of 13 items and submitted the remaining 37 items for purification and refinement as described in the following section. These items represent 74 percent of the initial items, which is acceptable in scale development research (See Babin, Darden, and Griffin 1994; Toncar et al. 2006; Yi and Gong 2013).

\section{Measure Purification}

The second step in developing the VCC model entailed administering the instrument to 332 business undergraduates drawn from two universities in the
United States. Data analysis was conducted on 327 (136 males, 191 females) data points as five of the subjects were removed due to incompletion. The participants ranged in age from 18 to 75 with the mean being 30. The sample reflected some degree of ethnic diversity: Caucasian, 76.5 percent; Hispanic, 15.4 percent; African American, 1.5 percent; Native American, 0.6 percent; and Asian, 0.6 percent. Student participation was secured in exchange for course credit. The survey instrument-comprised of demographic questions and 37 randomly ordered value co-creation items-was administered through an online commercial survey site. The participants were informed that the purpose of the survey was to explore if "customers actually create some of the value they receive from the purchase and/or use of a product and/or service experience" (See Appendix A for complete survey instructions). Similar to the procedure used by Sierra and McQuitty (2005), each respondent was instructed to think about a specific existing product or service when answering the questionnaire. Appendix B indicates the frequency counts for various product/service industry types identified by the respondents. The 37items were based upon a Likert scale, ranging from 1 to 7, anchored by "Strongly Disagree" and "Strongly Agree," respectively.

After confirming that the data met the multivariate normal assumption, an exploratory factor analysis using maximum likelihood was conducted to control for any items displaying low communalities, based on the recommendation of Fabrigar et al. (1999). The data was first examined for univariate outliers by investigating the boxplots for each variable using SPSS. Although some outliers were detected for one Dialogue variable and four Access variables, after careful consideration, we determined that the responses were truly representative of our population (Hair et al. 2010), as each respondent chose which company/brand to refer to while completing the questionnaire. We note that the companies chosen by these respondents were represented by retailers such as Target, The Banana Republic, McDonalds, Starbucks; telecommunications and cable companies such as AT\&T and Charter; and soft drink brands such as Coca Cola and Pepsi. Thereafter, we used AMOS to calculate Mahalanobis $\mathrm{D}^{2}$ (square distance) to examine the data for multivariate outliers (Byrne, 2010; Hair et al. 2010). However, as removing outliers can be risky because it can jeopardize the generalizability of the results (Hair et al. 2010), we 
decided to keep all data points at this stage as we had already established that the data were representative of our respondents. Missing data were handled through pair-wise deletion. One item of the Access dimension (The provider does his/her best to provide 24/7 access to the service/product experience) displayed a low communality (.318) and was, therefore, deleted from further analysis. A second exploratory factor analysis using maximum likelihood and an orthogonal rotation (varimax) was performed on the 36 remaining items. Bartlett's test of sphericity was significant at the $<.001$ level, and the Kaiser-Meyer-Olkin Measure (KMO) of sampling adequacy was very high at $\mathbf{9 6}$.

The first rotated factor analysis solution suggested five factors. The first factor included the nine items reflecting the Dialogue dimension of VCC. Two of the Access items loaded on the first factor and were, therefore, deleted from further analysis: 1 . The provider tries to maximize the customer's choice for when, where, and how the customer participates in the design and delivery of the product/service offering; 2 . The provider solicits customer input regarding how the service/product offering should be delivered in order to facilitate a positive experience.

Ten Transparency items were captured by the second factor, but several items that crossloaded on two other factors were removed from further analysis: 1 . The provider openly shares all information with the customer to insure a quality product/service experience; 2 . The provider openly provides information that might be helpful to improve the outcomes of the service/product experience; 3 . The provider treats the customer as a partner by disclosing all information relevant to a successful service/product experience; 4 . The provider emphasizes transparency in sharing information with the customer; 5 . The provider makes every attempt to make all aspects of the design and delivery process transparent to the customer; 6 . The provider gives customer information that makes it easier to compare the service/product offering with other competitive offerings.

Seven items loaded on the third factor that assessed consumer Risk Assessment. The fourth factor captured six of the Access items. However, three items crossloaded on the first factor (Dialogue dimension) and were, therefore, eliminated: 1 . The customer has many choices in how he/she participates in the design and delivery of the product/service offering; 2 . The provider allows the customer to select the service experience/ product design characteristics he/she desires; 3 . The provider is able to customize the service/product offering to an acceptable degree to suite the customer's needs and preferences.

Two Risk Assessment items: 1. The provider and customer understand that the customer is partially responsible for the outcomes associated with the product/ service experience and 2. The customer is fully aware that he/she contributes to the service/ product experience and therefore assumes responsibility for any inherent risks loaded highly on the fifth factor and were subsequently deleted from further analysis.

Use of eigenvalues of over 1 is the least accurate method to determine the number of factors to retain because this calculation often yields too many factors (Velicer and Jackson 1990). Thus, based on DeVellis (2003) recommendation, we used Catell's Scree test to determine the number of factors to retain. An examination of the scree plot suggested a five-factor solution accounting for 76 percent of the variance. Because of the difficulty in interpreting the elbow in the scree plot correctly, other researchers, such as Costello and Osborn (2005), suggest running the analysis with different numbers of factors (close to the elbow and guided by a priori theory). However, after deleting the crossloading items from the above analysis, the 23 remaining items loaded on four factors, accounting for 74 percent of the variance, without specifying the number of factors.

As recommended for purifying and developing a good fitting measurement model (Gerbing and Anderson 1988), we subjected the covariance matrix for the 23 items to a confirmatory factor analysis (CFA) using AMOS 18. A four-factor model specified to represent the four correlated factors using maximum likelihood extraction yielded an acceptable fitting model chi-square $=543.6, \mathrm{df}=224$ with all items loading significantly on their respective factors (Table 1). The root mean square error of approximation (RMSEA), which provides a good measure of fit for large sample sizes, was .066, falling within the acceptable range from .05 to .08 for large sample sizes (Hair et al. 2010; Meyers, Gamst, and Guarino 2006; Ping 2004; Rigdon 1998). Two other robust indices, the Tucker Lewis Index (NNFI) (Bentler and Bonett 1980) and the CFI (Bentler 1990) clearly displayed acceptable fit with .934 and .946 , respectively.

Internal consistency was assessed using Cronbach's alpha, construct reliability, and average variance 
Table 1

Factor Loadings - 23 Items

Item

Dialogue

Access

Risk-Assessment Transparency

The provider communicates with the customer to receive input on improving the $0.78(0.80)$ service/product experience.

The provider is interested in communicating with the customer about the best $0.78(0.78)$ ways to design and deliver a quality service/product experience.

The provider uses multiple channels of communication to encourage greater exchange of ideas with the customer about the service/product experience.

The provider and the customer have active dialogue on how to add value in the $0.73(0.81)$ service / product experience.

The customer is encouraged to communicate with the provider about any and all $0.71(0.78)$ aspects of the service/product experience.

Multiple lines of communications are used by the provider to gather input and $0.70(0.77)$ ideas from the customer.

The provider actively promotes dialogue with the customer to learn more about $0.68(0.85)$ the customer's reaction to the service/product experience.

The customer has many opportunities to share his/her ideas with the provider $0.66(0.82)$ about adding value to the service/provider experience.

The provider makes it easy for the customer to communicate his/her ideas about $0.65(0.76)$ the design and delivery of the service/product experience.

The provider lets the customer decide how he/she receives the service/product offering.

The customer has many options to choose how he/she experiences the service/ product offering.

It is easy for the customer to receive the service/ product offering when, where and how he/she wants it.

The provider provides the customer with comprehensive information pertaining how risks and benefits were assessed for the service experience or product.

The customer receives comprehensive information pertaining to the risks and benefits of the service/product experience.

The provider fully informs the customer about all risks stemming from product or service use.

The provider provides the customer with necessary tools and support to make fully informed decisions as to whether he or she should participate in the service/ product experience.

The provider is very clear and factual about both the negative and positive factors associated with the service/ product offering.

The provider allows the customer to make informed decisions regarding the risks and benefits of the product /service experience.

The provider encourages the customer to familiarize himself/herself with the risks associated with the service/product experience.

The provider fully discloses to the customer information which might be helpful to improve the outcomes of the service/ product experience.

The customer is given open access to information that might be useful in enhancing the overall design and delivery of the service/product experience.

The customer and provider are treated as equal partners in sharing information that is needed to achieve a successful service/product experience.

The provider fully discloses the customer detailed information regarding the costs and pricing associated with the design and delivery of the service/ product experience.

(Numbers in parentheses are factor loading results from Study 2, the 22 item DART scale) Note: ${ }^{1}$ Item dropped in Study 2 
Table 2

Summary of Statistics and Measurement Results

\begin{tabular}{|c|c|c|c|c|c|c|c|c|c|}
\hline Constructs and Items & Mean & Standard Deviation & AVE & Cronbach's $\alpha$ & & & & & \\
\hline Dialogue (D) & & & 0.66 & 0.95 & & & & & \\
\hline D1 & 5.00 & 1.61 & & & & & & & \\
\hline D2 & 5.08 & 1.62 & & & & & & & \\
\hline D3 & 5.14 & 1.58 & & & & & & & \\
\hline D4 & 4.55 & 1.67 & & & & & & & \\
\hline D5 & 5.18 & 1.54 & & & & & & & \\
\hline D6 & 5.02 & 1.51 & & & & & & & \\
\hline D7 & 4.76 & 1.55 & & & & & & & \\
\hline D8 & 4.52 & 1.62 & & & & & & & \\
\hline D9 & 4.66 & 1.61 & & & & & & & \\
\hline Risk-Assessment (R) & & & 0.65 & 0.86 & & & & & \\
\hline R2 & 4.43 & 1.58 & & & & & & & \\
\hline R3 & 4.48 & 1.55 & & & & & & & \\
\hline R4 & 4.55 & 1.51 & & & & & & & \\
\hline R5 & 4.27 & 1.61 & & & & & & & \\
\hline R6 & 4.76 & 1.48 & & & & & & & \\
\hline R7 & 5.14 & 1.30 & & & & & & & \\
\hline R8 & 4.57 & 1.43 & & & & & & & \\
\hline Access (A) & & & 0.72 & 0.89 & & & & & \\
\hline A3 & 5.41 & 1.49 & & & & & & & \\
\hline A4 & 5.29 & 1.50 & & & \multirow{2}{*}{\multicolumn{5}{|c|}{ Squared phi-correlation matrix }} \\
\hline A5 & 5.32 & 1.45 & & & & & & & \\
\hline Transparency $(T)$ & & & 0.61 & 0.93 & & D & A & $\mathbf{R}$ & $\mathbf{T}$ \\
\hline $\mathrm{T} 1$ & 5.09 & 1.56 & & & D & 1.00 & & & \\
\hline T3 & 4.48 & 1.55 & & & A & 0.45 & 1.00 & & \\
\hline T4 & 4.74 & 1.51 & & & $\mathbf{R}$ & 0.42 & 0.26 & 1.00 & \\
\hline T10 & 4.70 & 1.60 & & & $\mathbf{T}$ & 0.55 & 0.42 & 0.45 & 1.00 \\
\hline
\end{tabular}

extracted (AVE) (see Table 2 for summary of statistics). All four factors met or exceeded accepted standards for Cronbach's alpha (Nunnally 1978): Dialogue $=.95 ;$ Access $=.89 ;$ Risk Assessment $=.86$; and Transparency $=.93$. Construct reliability, which offers a means with which to assess internal consistency, does not assume unidimensionality like Cronbach's alpha (Hair et al. 2010; Ping 2004). The calculated construct reliability for each factor ranged from 0.86 to 0.95 . Each figure was identical to its respective alpha, thus providing further support for the unidimensionality and internal consistency of each construct. The average variance extracted (AVE) provides an assessment of the amount of variance captured by the measurement of the construct relative to random measurement error. An AVE of .50 or higher indicates high internal consistency (Fornell and Larker 1981; Ping 2004). The calculated AVE in this research exceeded .50 for all factors: Dialogue $=$
$.66 ;$ Access $=.72 ;$ Risk Assessment $=.65$ and Transparency $=.61$. To test for discriminant validity, we first compared the square of the $\phi$ - (phi) coefficient to the AVE for the factors. The square of the $\phi-$ coefficient was less than the AVE for all of the correlations, thus supporting discriminant validity.

\section{STUDY 2: VALIDATING THE DART SCALE}

The purpose of Study 2 is to validate the DART measurement model developed in Study 1. By utilizing several steps suggested by Gerbing and Anderson (1988), the model was further assessed through examining item purification, convergent, discriminant and nomological validity, and the reliability of the scale.

The VCC literature stresses the integration of the consumer within the network of the firm, which 
includes its value chain partners. Related research grounded in Lawler's (2001) social exchange theory, explores how the level of jointness (i.e., shared responsibility) in an exchange transaction affects ties and commitments in various forms of relationships. Specifically, research demonstrates that shared responsibility is a key component to creating value and fostering customer loyalty (Sierra and McQuitty 2005; Sierra, Heiser, and McQuitty 2009). If the building blocks for a conducive experience environment exist, it is likely such contexts will also yield a greater sense of shared responsibility within the context of specific service encounters as well as "greater interdependence among the main actors (consumer and producers), which in turn builds trust and sustains relationships" (Sheth and Uslay 2007 , p. 305). The power of communal feelings of brand commitment in building repeat purchase intentions and brand loyalty is similarly supported in research on brand tribalism and related forms of brand community (Taute and Sierra 2014). Collectively, these theoretical bases suggest that conditions that promote connectedness and contributions of the consumer to consumption outcomes should ultimately yield enhanced loyalty and commitment to the customer-provider relationship. Thus, we posit that experience environments characterized by high DART measures should be positively related to increased feelings of shared responsibility as well as enhanced loyalty and commitment to the customer-provider relationship.

\section{H1: Shared responsibility is positively related to high DART assessment.}

\section{H2: High DART assessment is positively related to loyalty toward the provider.}

To examine the hypothesized relationships, the 23item DART scale, a 5-item scale measuring service loyalty adapted from Raju (1980), and a 4-item scale measuring beliefs about shared responsibility (Sierra and McQuitty 2005; Sierra, Heiser, and McQuitty 2009) (see Appendix D) were administered online to a second sample of 269 students (course credit was offered as an incentive at the same two U.S. universities as in Study 1). The second sample, comprised of 47 percent women $(\mathrm{n}=126)$ and 53 percent men $(\mathrm{n}=143)$, ranged in age from 18 to 61 with a mean of 24 years. In terms of ethnicity, 71.4 percent of the sample were Caucasian;
18.6 percent were Hispanic; 2.2 percent, African American; .7 percent, Native American; and 2.6 percent, Asian. As in the previous study, we examined the data $(\mathrm{N}=269)$ for univariate outliers using SPSS and boxplots for each variable. Although the data reflected some outliers for the Dialogue, Access and Risk-Assessment variables, only one outlier was removed from the data. The authors determined that the remaining suggested outliers to be truly representative of the population (Hair et al. 2010). Again, as in Study 1, an interesting note in regards to these data points is that as we asked each respondent to choose the company/brand to think of while completing the questionnaire. The companies represented in this category were predominantly telecommunication companies, cable TV, and computer hardware companies (e.g., Verizon, Sprint, AT\&T, T-mobile, Hewlett Packard, Comcast, and Apple).

\section{Item Purification}

To purify the 23 scale items, we performed a CFA with the four factors found in Study 1; this operation yielded a chi-square of 522.1 at 224 degrees of freedom. All items, except for one risk-assessment item (.49)-The provider allows the customer to make informed decisions regarding the risks and benefits of the product /service experience-loaded significantly on their respective factors (see Table 1) providing evidence for convergent validity. The model fit was acceptable with $\mathrm{NNFI}=.915, \mathrm{CFI}=.931$, and RMSEA $=.07$ (Bentler and Bonett 1980; Bentler 1990; Hair et al. 2010; Ping 2004; Rigdon 1998).

\section{Construct Validation}

All four constructs had acceptable calculated construct reliabilities (0.83-0.94) (see Table 3). The discriminant validity of the scale items was evaluated using the average variance extracted (AVE) procedure. As mentioned earlier, an AVE of .50 or higher indicates high internal consistency (Fornell and Larker 1981; Ping 2004). Although the AVE values were slightly lower than in Study 1, as indicated in Table 3, the values for all of the DART dimensions were above .50 : Dialogue $=62 \%$; Access $=62 \%$; RiskAssessment $=63 \%$ and Transparency $=57 \%$. The square of the $\phi$ - coefficient for the four factors was compared to AVE and all of them were lower than 
Table 3

Summary of Statistics and Measurement Results

\begin{tabular}{|c|c|c|c|c|c|c|c|c|c|c|}
\hline Constructs and Items & Mean & Standard Deviation & AVE & Cronbach's $\alpha$ & & & & & & \\
\hline Dialogue (D) & & & 0.62 & 0.94 & & & & & & \\
\hline D1 & 5.33 & 1.37 & & & & & & & & \\
\hline D2 & 5.32 & 1.41 & & & & & & & & \\
\hline D3 & 5.27 & 1.42 & & & & & & & & \\
\hline D4 & 4.75 & 1.54 & & & & & & & & \\
\hline D5 & 5.28 & 1.43 & & & & & & & & \\
\hline D6 & 5.08 & 1.53 & & & & & & & & \\
\hline D7 & 4.99 & 1.49 & & & & & & & & \\
\hline D8 & 4.79 & 1.51 & & & & & & & & \\
\hline D9 & 4.78 & 1.54 & & & & & & & & \\
\hline Risk-Assessment (R) & & & 0.63 & 0.92 & & & & & & \\
\hline R2 & 4.32 & 1.60 & & & & & & & & \\
\hline R3 & 4.60 & 1.57 & & & & & & & & \\
\hline R4 & 4.60 & 1.57 & & & & & & & & \\
\hline R5 & 4.37 & 1.62 & & & & & & & & \\
\hline R6 & 4.89 & 1.50 & & & & & & & & \\
\hline R8 & 4.47 & 1.53 & & & & & & & & \\
\hline Access $(A)$ & & & 0.62 & 0.83 & & & & & & \\
\hline A3 & 5.66 & 1.36 & & & & & & & & \\
\hline A4 & 5.44 & 1.37 & & & & & & & & \\
\hline A5 & 5.56 & 1.33 & & & & & & & & \\
\hline Transparency $(T)$ & & & 0.57 & 0.84 & & & & & & \\
\hline $\mathrm{T} 1$ & 5.51 & 1.46 & & & & & & & & \\
\hline T3 & 4.72 & 1.51 & & & & & & & & \\
\hline T4 & 4.98 & 1.52 & & & & & & & & \\
\hline T10 & 4.81 & 1.56 & & & \multirow{2}{*}{\multicolumn{6}{|c|}{ Squared phi-correlation matrix }} \\
\hline $\begin{array}{l}\text { Shared Responsibility (SR) } \\
\text { SR1 }\end{array}$ & 4.35 & 1.50 & $0.48^{\prime}$ & 0.78 & & & & & & \\
\hline SR2 & 4.93 & 1.46 & & & & D & A & $\mathbf{R}$ & $\mathbf{T}$ & SR \\
\hline SR3 & 5.09 & 1.32 & & & D & 1.00 & & & & \\
\hline SR4 & 4.69 & 1.50 & & & A & 0.49 & 1.00 & & & \\
\hline \multirow{2}{*}{\multicolumn{5}{|c|}{$\begin{array}{l}\text { Note: }{ }^{1} \text { The squared Phi-coefficient was lower than AVE at } 0.36 \text { still } \\
\text { suggesting discriminant validity }\end{array}$}} & R & 0.52 & 0.52 & 1.00 & & \\
\hline & & & & & SR & $\begin{array}{l}0.50 \\
0.19\end{array}$ & $\begin{array}{l}0.41 \\
0.18\end{array}$ & $\begin{array}{l}0.28 \\
0.21\end{array}$ & $\begin{array}{l}1.00 \\
* 0.36\end{array}$ & 1.00 \\
\hline
\end{tabular}

the AVE, further suggesting discriminant validity (see Table 3). A final CFA was performed to confirm parsimonious fit. After the dropped risk-assessment item during the item purification step, this yielded a chisquare of 421.15 at 203 degrees of freedom with fit indices NNFI $=.935$, CFI $=.948$, and RMSEA $=.063$. All 22 items loaded significantly on their respective factors (Figure 1). (See Appendix C for the final DART scale items.)

To further assess construct validity, we examined the correlations between each factor and the variables discussed above (i.e., shared responsibility and service loyalty). First, we ran a CFA with shared responsibility as a fifth construct to ensure that shared responsibility was different from the four co-creation dimensions. As Table 3 illustrates, the shared responsibility construct displayed a calculated construct reliability of 0.78 and an AVE lower than .50, at .48. However, when comparing the squared $\phi$-coefficient, it was lower than AVE at 0.36, suggesting discriminant validity. The interconstruct correlations between shared responsibility and the four DART dimensions were significant and positive: Dialogue $r=.44, \alpha=.01$; Access $r=.43, \alpha=.01$; Risk Assessment $=.46, \alpha=.01$ and Transparency $r=.60, \alpha=.01$. 
Figure 1

\section{Results of CFA-model of DART Scale Dimensions}

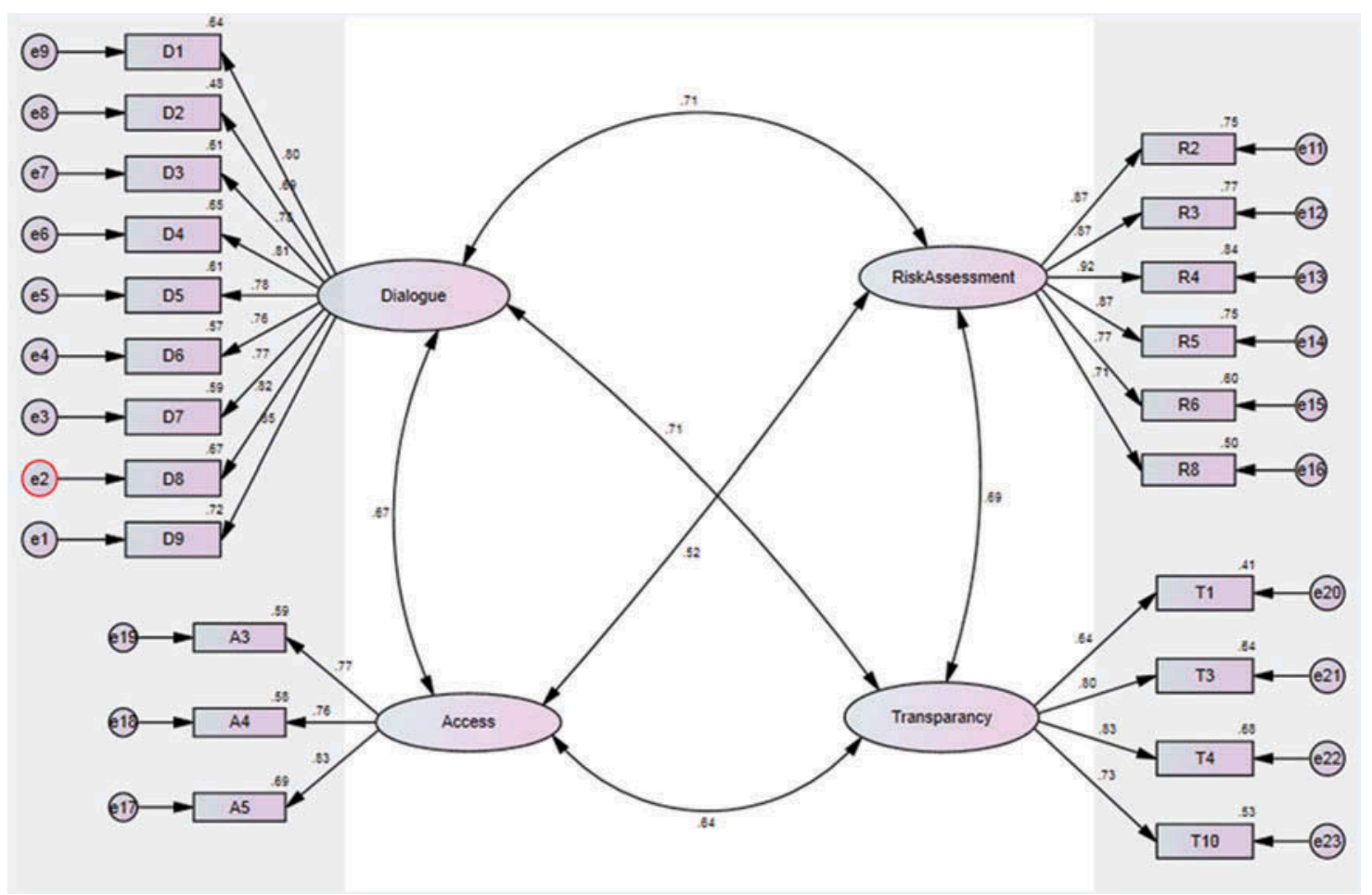

Next, service loyalty was added to the model with the four DART factors; however, its correlation with the latter was relatively low: Dialogue $=.07$; Access $=.237$; Risk $=.102$; and Transparency $=.159$. To assess nomological validity, we evaluated the strength of relationships between shared responsibility, the DART components, and service loyalty by testing our hypotheses using structural equation modeling (See Figure 2). A covariance matrix and maximum likelihood estimation were used to estimate the model. Missing data were handled using pair-wise deletion. The six constructs with four, nine, six, three, four, and five items were included (Shared responsibility, Dialogue, Risk Assessment, Access, Transparency, and Loyalty). The resulting goodness-of-fit statistics suggests a good fit of the model to the data, as chi-square $=1052.2, \mathrm{df}=$ $426, \mathrm{CFI}=.879, \mathrm{NNFI}=.86$, and RMSEA $=.074$. Some of these statistics suggest moderate fit, such as the NNFI and the CFI (Hu and Bentler 1999), whereas RMSEA implies a good fit (Browne and Cudeck 1993; Meyers, Gamst, and Guarino 2006). However, because of our large sample size, we also had to examine the model fit

\section{Figure 2 \\ Measurement Model (SEM)}

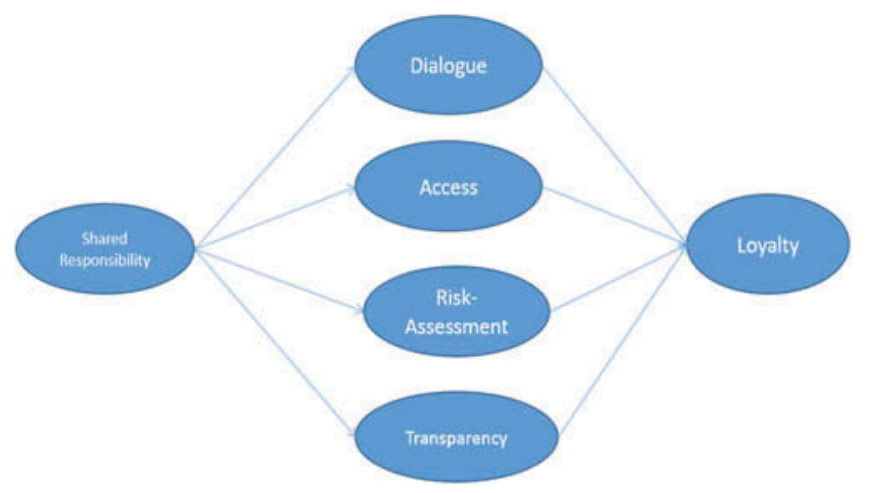

and goodness-of-fit statistics in consideration with the model's statistical power, as high power allows for a "more relaxed interpretation" of these statistics (McQuitty 2004, p. 182). Post hoc analysis of power was conducted for each path coefficient and $R^{2} S$ confirming the model's predictive power (Gaskin 2013; 
Table 4

Structural Results

\begin{tabular}{|c|c|c|c|c|c|}
\hline \multicolumn{2}{|c|}{ First order Structural Estimates } & \multirow{2}{*}{$\frac{\text { Hypothesis }}{\mathrm{H} 1^{\mathrm{a}}}$} & \multirow{2}{*}{$\frac{\text { Estimate }}{0.80}$} & \multirow{2}{*}{$\frac{\mathbf{t}}{10.09}$} & \multirow{2}{*}{$\frac{\text { p-value }}{<0.01}$} \\
\hline Shared Responsibility & $\rightarrow$ Dialogue & & & & \\
\hline Shared Responsibility & $\rightarrow$ Access & $\mathrm{H} 1^{\mathrm{a}}$ & 0.72 & 8.97 & $<0.01$ \\
\hline Shared Responsibility & $\rightarrow$ Risk-Assessment & $\mathrm{H} 1^{\mathrm{a}}$ & 0.77 & 10.25 & $<0.01$ \\
\hline Shared Responsibility & $\rightarrow$ Transparency & $\mathrm{H} 1^{\mathrm{a}}$ & 0.88 & 8.69 & $<0.01$ \\
\hline \multicolumn{6}{|c|}{ Second-order Structural Estimates } \\
\hline Dialogue & $\rightarrow$ Service Loyalty & $\mathrm{H} 2^{\mathrm{b}}$ & -.20 & -1.73 & 0.08 \\
\hline Access & $\rightarrow$ Service Loyalty & $\mathrm{H} 2^{\mathrm{a}}$ & 0.30 & 2.46 & $<0.01$ \\
\hline Risk-Assessment & $\rightarrow$ Service Loyalty & $\mathrm{H} 2^{\mathrm{b}}$ & 0.01 & 0.18 & 0.86 \\
\hline Transparency & $\rightarrow$ Service Loyalty & $\mathrm{H} 2^{\mathrm{b}}$ & .10 & 0.73 & 0.47 \\
\hline \multicolumn{6}{|l|}{$\mathrm{H} 1^{\text {a }}$ Supported } \\
\hline \multicolumn{6}{|l|}{$\mathrm{H} 2^{\mathrm{a}}$ Supported } \\
\hline \multicolumn{6}{|l|}{$\mathrm{H} 2^{\mathrm{b}}$ Not Supported } \\
\hline \multicolumn{6}{|l|}{ Global Fit Indices } \\
\hline \multicolumn{6}{|c|}{$X$-square $=1052.2, d f=426$} \\
\hline \multicolumn{6}{|c|}{$\mathrm{CFI}=.879$} \\
\hline \multicolumn{6}{|l|}{$N N F I=.86$} \\
\hline RMSEA $=.074$ & & & & & \\
\hline
\end{tabular}

Lowry and Gaskin 2014). The structural equation model's path coefficients were used to evaluate the hypotheses (See Table 4).

Hypothesis 1 (H1) concerns the positive relationship between shared responsibility and the DART items. The relationship between shared responsibility and Dialogue had a standardized structural coefficient of .80 with a $t$-statistic of $10.09(\mathrm{p}<.01)$, and the standardized coefficient between shared responsibility and Risk was .77 with a t-statistic of 10.25 ( $p<.01$ ). The standardized coefficient between shared responsibility and Transparency was .88 with a $t$-statistic of 8.69 ( $\mathrm{p}<.01)$, and the standardized coefficient between shared responsibility and Access was .72 with a $t$-statistic of $8.97(\mathrm{p}<.01)$. These results strongly support H1. Hypothesis 2 (H2) posits that DART is positively related to consumer loyalty toward the provider. The structural coefficients for the relationships between the DART items and loyalty were only significant for the Access construct at .30 with a $t$-statistic of $2.46(\mathrm{p}<.01)$. The other path coefficients were $-.20(\mathrm{t}=-1.75, \mathrm{p}=.08)$ for Dialogue; $.01(\mathrm{t}=0.18$, $\mathrm{p}=.86)$ for Risk; and .10 ( $\mathrm{t}=.73, \mathrm{p}=.47)$ for Transparency. Thus, H2 was only partially supported. The data and structural equation model support H1 that shared responsibility is positively related to VCC, but only partially support $\mathrm{H} 2$ that DART is positively related to loyalty (See Table 4).

\section{DISCUSSION}

Scholars emphasize VCC as the new frontier of competitive advantage where connected, educated, and vocal consumers actively participate in customized design and/or delivery options (Prahalad and Ramaswamy 2004b). Firms are expected to integrate VCC opportunities to a much greater extent, as the prevailing business logic, in which the firm is the center of value creation, shifts to one emphasizing relationships, intangibles, value co-creation, and service provision (Prahalad and Ramaswamy 2002; Vargo and Lusch 2004). Intimately associated with this shift is the trend of consumers seeking opportunities for interaction with organizations in order to augment the overall value they derive from their individual consumption experiences.

While prior research has explored how corporations foster co-creation, little has been done in terms of developing measures that assist the firm in making the shift in orientation. To date, psychometrically valid scales relevant to VCC are limited (Chan, Yim, and Lam 2010; Sierra, Heiser, and 
McQuitty 2009; Vernette and Hamdi-Kidar 2013; Yi and Gong 2013; Yim, Chan, and Lam 2012), and existing measures have focused on the service encounter, in particular the characteristics of consumers. The research presented here contributes to the VCC literature and practice by introducing the development and validation of a scale that assesses a given organization's experience environment and its readiness to engage in VCC efforts. The DART scale, based upon the works of Prahalad and Ramaswamy (2004a, 2004b) that posit dialogue, access, risk assessment, and transparency as the key components of a VCC engagement, provides a valuable tool for those organizations embarking on strategic VCC efforts. The following section explores the implications of the DART scale for organizations.

\section{Managerial Implications}

In order to capitalize on VCC opportunities, organizations must consider the full scope of their network operations and interactions. If a firm chooses to pursue a VCC strategy, it is a source of sustainable competitive advantage that does not simply affect marketing; indeed, it affects the entire firm, its network structures, and its management processes. Adopting a VCC strategy requires a firm to modify its practices, policies, and organizational structure in order to deliberately facilitate VCC with consumers and other parties in its production, design, and delivery processes. The information gathered from administering the DART instrument provides the organization with an understanding of how its current configuration of policies, procedures, and structures facilitates or obstructs meaningful customer/partner/firm interactions in an environment of openness and reciprocal value creation. Additionally, as the DART scale assesses readiness in four specific areas, the organization gleans insight as to how its current configuration affects different components of VCC. For example, a company whose results indicate poor readiness in dialogue should carefully examine and improve open lines of communication connecting all participants in the value chain. Poor evaluations of dialogue should prompt scrutiny of communication channels within and across firm/ partner/consumer communities to identify poor response times and/or barriers in information flow and exchange. Similarly, access deficiencies should trigger focused review of rules and policies for structural and information access that may reveal things that exist more as historical artifact than as purposeful requirements. Once selected changes are implemented, an organization can readminister the scale to assess the extent to which the changes affect the organization's preparedness to undertake VCC endeavors. Results of the assessments can and should be shared with the network of suppliers and entities as a form of self-diagnosis to promote brainstorming and reflection upon strengths and weaknesses of the experience environment. Changes in technology, political/regulatory requirements, and sociocultural conditions mandate continual environmental scanning. When such analysis is coupled with DART scale data, managers may better recognize and realize the potential benefits of change to internal operating policies and procedures in the context of the experience environment.

Managers might also survey other value chain partners with the DART scale to determine if there are gaps in perceptions of the experience environment between customers and other interaction participants. Although customer perceptions are likely most relevant, identifying discrepancies in perspective might provide insights to possible weaknesses in the business community connections. If partners responsible for particular functions or processes are "out-of-touch" with the experiences of the consumer (as reflected by measurement gaps), then that interactive area of the experience environment may require further investigation to identify the source of the difference in perceptions of the experience.

Of course, DART data may not always mandate changes to existing operations. Low dimension ratings may force firms to confront tough choices regarding what is necessary to make the paradigmatic shift to value co-creation strategies and determine if VCC is the best source of competitive advantage for the firm. If a firm operates in an industry where allowing consumer modifications to product design might lead to excessive hazards to value chain partners (e.g., the customers themselves, employees, suppliers), the firm may question if VCC in all spheres of the experience environment is wise. Alternatively, the firm may explore if improved communication regarding the risks and related liabilities can adequately assuage the consumers in the rejection of product design ideas.

Ultimately, a firm that seeks to cocreate value with its customers must decide how and where consumers 
can extract value, how to manage the firm-customer engagement, and how structurally and procedurally to enable co-creation as envisioned. For example, Dell Computers engages consumers through individualized production design processes, whereas Apple facilitates iPhone customer value extraction through alternative selection and configuration of iPhone applications. Thus, although each company must independently pinpoint the nexus of value co-creation opportunities, there is a commonality of traits that typify those firms best suited and prepared to embark on such a journey. Firms that desire to centralize the consumer's role in its value creation process must develop and institute new business models, customer interfaces, and customer interaction systems that have a high internal and external configurational fit that facilitates collaboration with customers (Berger et al. 2005; Nenonen and Storbacka 2010; Sawhney, Verona, and Prandelli 2005). Ducati, for example, organized its marketing department around its fan (i.e., consumer) community and connected the community management function with the new product development function (Sawhney, Verona, and Prandelli 2005). Indeed, "true co-creation will require a fundamental redesign of marketing processes and the marketing organization to support continuous dialogue with customers, as well as to systematically share the knowledge generated through this dialogue within the firm" (Sawhney, Verona, and Prandelli 2005, p. 12).

\section{Limitations}

With respect to potential limitations of this research, the use of a student sample may constitute a limitation as such samples may not be representative of all consumers (e.g., Winer 1999). However, students are also consumers and, thus, it is reasonable to utilize student samples to develop and validate the initial forms of survey instruments. In order to further refine the DART scale and establish generalizability of results, future research must include samples that include more diversity in background factors including industry and age ranges. On a related note, an additional limitation is the inability to assess the robustness of the scale across various goods/service sectors. Although respondents were asked to consider a specific product or service organization when answering the questionnaire, the data indicate the use of a range of products and services for this purpose. Thus, future research could entail a more controlled approach to the scale's use across products/services sectors.

\section{Future Research}

While our analysis supports the structural legitimacy of the DART instrument, it does suggest that additional exploration is necessary to understand fully the cause and effect relationships associated with VCC processes. Specifically, the current research does not support a strong and positive effect of high DART measures with customer loyalty. This may reflect limitations related to the current research, or it may simply suggest that there is a need to more systematically study the relationship across several related and important VCC constructs. Although a firm's experience environment may, indeed, be conducive to VCC, the targeted consumers may view high customer participation as a burden rather than an opportunity. Bendapudi and Leone (2003), for example, found that customers who are highly involved in co-creation efforts attribute to themselves the greater share of credit for the success of such efforts and, in turn, devalue the relationships with the product or service providers. Thus, VCC may engender self-serving bias in some consumers thereby leading to the nonsupported hypothesis with respect to customer loyalty. Clearly, such considerations deserve greater attention and study. Future research could also consider the differential importance of relationships across the DART components and other variables of interest in service-dominant frameworks. Although Prahalad and Ramaswamy (2000) suggest that managers can combine the different building blocks of co-creation to develop value, future research must explore the veracity of this assumption.

\section{REFERENCES}

Babin, Barry J., William R. Darden, and Mitch Griffin (1994), "Work and/ or Fun: Measuring Hedonic and Utilitarian Shopping Value," Journal of Consumer Research, 20 (4), 644-56.

Bearden, William O., R. Bruce Money, and Jennifer L. Nevins (2006), "A Measure of Long-Term Orientation: Development and Validation," Journal of the Academy of Marketing Science, 34 (3), 456-67.

—, Richard G. Netemeyer, and Jesse E. Teel (1989), "Measurement of Consumer Susceptibility to Interpersonal Influence," Journal of Consumer Research, 15 (March), 473-81. 
Bendapudi, Neeli, and Robert P. Leone (2003), "Psychological Implication of Customer Participation in Co-production," Journal of Marketing, 67 (1), 14-28.

Bentler, Peter M. (1990), "Comparative Fit Indexes in Structural Models," Psychological Bulletin, 107 (2), 238-46.

—, and Douglas G. Bonett (1980), "Significance Tests and Goodness-of-fit in the Analysis of Covariance Structures," Psychological Bulletin, 88 (3), 588-606.

Berger, Christoph, Kathrin Möslein, Frank Piller, and Ralf Reichwald (2005), "Co-designing Modes of Cooperation at the Customer Interface: Learning from Exploratory Research," European Management Review, 2 (1), 70-87.

Browne, Michael W., and Robert Cudeck (1993), "Alternative Ways of Assessing Model Fit," in Testing Structural Equation Models, Bollen, K. A. and Long, J. S., eds., Beverly Hills, CA: Sage.

Byrne, Barbara M. (2010) Structural Equation Modeling with AMOS: Basic Concepts, Application and Programming, 2nd ed., New York: Routledge.

Chan, Kimmy Wa, Chi Kin Yim, and Simon S. K. Lam (2010), "Is Customer Participation in Value Creation a Double-Edged Sword? Evidence from Professional Financial Services across Cultures," Journal of Marketing, 74 (3), 48-64.

Churchill, Gilbert A. (1979), "A Paradigm for Developing Better Measures of Marketing Constructs," Journal of Marketing Research, 61 (January), 68-84.

Costello, Anna B., and Jason W. Osborn (2005), "Best Practices in Exploratory Factor Analysis: Four Recommendations for Getting the Most From Your Analysis," Practical Assessment, Research and Evaluation, 10 (7), 1-9.

DeVellis, Robert F. (2003), Scale Development: Theory and Applications, 2nd ed., Applied Social Research Methods Series, Vol. 26, Thousand Oaks Park, CA: Sage Publications, Inc.

Fabrigar, Leandre R., Duane T. Wegener, Robert C. MacCallum, and Erin J. Strahan (1999), "Evaluating the Use of Exploratory Factor Analysis in Psychological Research," Psychological Methods, 13, 272-99.

Fornell, Claes, and David F. Larker (1981), "Evaluating Structural Equation Models with Unobservable Variables and Measurement Error," Journal of Marketing Research, 18, (February), 39-50.

Gaskin, James (2013), Post-hoc Power Analysis in SmartPLS and AMOS. Gaskination's Statistics. [Online] (available at http://youtube.com/Gaskination).

Gerbing, David W., and James C. Anderson (1988), “An Updated Paradigm for Scale Development Incorporating Unidimensionality and Its Assessment," Journal of Marketing Research, 25 (2), 186-92.

Grönroos, Christian, and Päivi Voima (2013), "Critical Service Logic: Making Sense of Value Creation and Co-creation," Journal of the Academy of Marketing Science, 41, 133-50.

— and — (2012), "Conceptualising Value Co-creation: A Journey to the 1970s and Back to the Future," Journal of Marketing Management, 28 (13-14), 1520-34.

Hair, Joseph F., Jr., William C. Black, Barry J. Babin, and Rolph E. Anderson (2010), Multivariate Data Analysis, 7th ed., Upper Saddle River, NJ: Pearson (Prentice Hall).
Hoyer, Wayne D., Rajesh Chandy, Matilda Dorotic, Manfred Krafft, and Siddharth S. Singh (2010), "Consumer Cocreation in New Product Development," Journal of Service Research, 13 (3), 283-96.

$\mathrm{Hu}$, Li-tze, and Peter M. Bentler (1999), “Cutoff Criteria for Fit Indexes in Covariance Structure Analysis: Conventional Criteria versus New Alternatives," Structural Equation Modeling, 6 (1), 1-55.

Lawler, Edward J. (2001), "An Affect Theory of Social Exchange," The American Journal of Sociology, 107 (2), 321-52.

Lowry, Paul B., and James Gaskin (2014), "Partial Least Squares (PLS) Structural Equation Modeling (SEM) for Building and Testing Behavioral Causal Theory: When to Choose It and How to Use It," IEEE Transactions on Professional Communication, 57 (2), 123-46.

Lusch, Robert F., and Stephen L. Vargo (2006), "Service-dominant Logic: Reactions, Reflections and Refinements," Marketing Theory 6 (3), 281-88.

McQuitty, Shaun (2004), "Statistical Power and Structural Equation Models in Business Research," Journal of Business Research, 57 (2), 175-83.

Meyers, Lawrence S., Glenn Gamst, and Anthony J. Guarino (2006), Applied Multivariate Research: Design and Interpretation, Thousand Oaks Park, CA: Sage.

Nenonen, Suvi, and Kaj Storbacka (2010), "Business Model Design: Conceptualizing Networked Value Co-creation," International Journal of Quality and Service Sciences, 2 (1), $4-59$.

Nunnally, Jum C. (1978), Psychometric Theory, 2nd ed., New York: McGraw-Hill.

Payne, Adrian F., Kaj Storbacka, and Pennie Frow (2008), "Managing the Co-creation of Value," Journal of the Academy of Marketing Science, 36, 83-96.

Ping, Robert A. (2004), "On Assuring Valid Measures for Theoretical Models using Survey Data," Journal of Business Research, 57 (2), 125-41.

Prahalad, C. K. (2004), The Future of Competition: Co-creating Unique Value with Customers, Boston: Harvard Business School Publishing.

—, and Venkatram Ramaswamy (2000), "Co-opting Customer Competence," Harvard Business Review, 78 (1), 79-87.

- , and (2002), "The Co-Creation Connection," Strategy + Business, 27 (Second Quarter), 50-61.

and - (2003), "The New Frontier of Experience Innovation," MIT Sloan Management Review, 44 (4), 12 18.

and - (2004a), "Co-Creation Experience: the Next Practice in Value Creation," Journal of Interactive Marketing, 18 (3), 5-14.

— Customers," Strategy \& Leadership, 32 (3), 4-9.

Raju, P.S. (1980), “Optimum Stimulation Level: Its Relationship to Personality, Demographics, and Exploratory Behavior," Journal of Consumer Research, 7 (3), 272-82.

Ramaswamy, Venkat (2011), “It's About Human Experiences... and Beyond, to Co-creation," Industrial Marketing Management, 40 (2), 195-96. 
_ Enterprise," Harvard Business Review, 88 (10), 100-109.

— , and Keriman Ozcan (2013), "Strategy and Co-creation Thinking," Strategy \& Leadership, 41 (6), 5-10.

Ramirez, Rafael (1999), "Value Co-production: Intellectual Origins and Implications for Practice and Research," Strategic Management Journal, 20, 49-65.

Rigdon, Edward E. (1998), "Structural Equation Modeling," in Modern Methods for Business Research, G. A. Marcoulides, ed., Mahwah, NJ: LEA, 251-94.

Roser, Thorsten, Alain Samson, Patrick Humphreys, and Eidi Cruz-Valdivieso (2009), Co-creation: New Pathways to Value: An Overview, London: Promise \& LSE Enterprise.

Sawhney, Mohanbir, Gianmario Verona, and Emanuala Prandelli (2005), "Collaborating to Create: The Internet as a Platform for Customer Engagement in Product Innovation," Journal of Interactive Marketing, 19 (4), 4-17.

Sheth, Jagdish N., and Can Uslay (2007), "Implications of the Revised Definition of Marketing: From Exchange to Value Creation," Journal of Public Policy and Marketing, 26 (2), 302-7.

Sierra, Jeremy J., Robert S. Heiser, and Shaun McQuitty (2009), "Exploring Determinants and Effects of Shared Responsibility in Service Exchanges," Journal of Marketing Theory and Practice, 17 (2), 111-28.

— - and Shaun McQuitty (2005), "Service Providers and Customers: Social Exchange Theory and Service Loyalty," Journal of Services Marketing, 16 (6), 392-400.

Skaržauskaitè, M. (2013), "Measuring and Managing Value Co-creation Process: Overview of Existing Theoretical Models," Socialinès technologijos/Social Technologies, 3 (1), 115-29.

Stemler, Steven E. (2004), "A Comparison of Consensus, Consistency, and Measurement Approaches to Estimating Interrater Reliability," Practical Assessment, Research \& Evaluation, 9 (4), October 30, 2014 (available at http://PAREonline.net/getvn.asp?v=9\&n=4).

\section{APPENDIX A}

Survey Instructions:

The following survey explores if you, as a customer, participate in creating some of the value that you receive from the purchase and use of a product or service.

To help us learn more about value co-creation in product/service experiences, think about a specific product brand or service provider that you utilize, or have utilized in the past. Examples of specific brands include Starbucks, Apple, and Bally Total Fitness centers (Note!
Taute, Harry A., and Jeremy J. Sierra (2014), "Brand Tribalism: An Anthropological Perspective," Journal of Product \& Brand Management, 23 (1), 2-15.

Tian, Kelly T., and Karyn McKenzie (2001), "The Long-Term Predictive Validity of the Consumers' Need for Uniqueness Scale," Journal of Consumer Research, 10 (3), 171-93.

Toncar, Mark F., Jane S. Reid, David J. Burns, Cynthia E. Anderson, and Hieu P. Nguyen (2006), "Uniform Assessment of the Benefits of Services Learning: The Development, Evaluation, and Implementation of the SELEB Scale," Journal of Marketing Theory and Practice, 14 (3), 223-38.

Vargo, Stephen L., and Robert F. Lusch (2004), "Evolving to a New Dominant Logic for Marketing," Journal of Marketing, 68 (January), 1-17.

Velicer, Wayne F., and Douglas N. Jackson (1990), "Component Analysis versus Common Factor-Analysis -Some Further Observations," Multivariate Behavioral Research, 25 (1), 97-114.

Vernette, Eric, and Linda Hamdi-Kidar (2013), "Co-creation with Consumers: Who Has the Competence and Want to Cooperate?" International Journal of Market Research, 55 (4), 2-20.

Wikström, Solveig (1996), "Value Creation by CompanyConsumer Interaction," Journal of Marketing Management, 12 (5), 359-74.

Winer, Russell S. (1999), "Experimentation in the $21^{\text {st }}$ Century: The Importance of External Validity," Journal of the Academy of Marketing Science, 27 (3), 349-58.

Yi, Youjae, and Taeshik Gong (2013), "Customer Value Cocreation: Scale Development and Validation," Journal of Business Research, 66, 1279-84.

Yim, Chi Kin (Bennett), Kimmy Wa Chan, and Simon S. K. Lam (2012), "Do Customers and Employees Enjoy Service Participation? Synergistic Effects of Self- and OtherEfficacy," Journal of Marketing, 75 (November), 121-40.

Zaichkowsky, J. L. (1985), "Measuring the Involvement Construct," Journal of Consumer Research, 12 (3), 341-52.

You can pick any brand you want-these are just examples). Please be specific in your brand selection and consider why you like, or dislike, this brand prior to rating your agreement/disagreement with each of the following statements.

In reading each statement, the term "provider" refers to the company/ individual(s) who offers the product/ service, and the "customer" is you and/or any others who purchase this product/ service. Please consider each statement carefully as it applies to your experience as a consumer of this brand. 


\section{APPENDIX B}

\begin{tabular}{lcc}
\hline & \multicolumn{2}{c}{ Sample $\mathbf{1}(\mathbf{n}=\mathbf{3 2 7})$} \\
\cline { 2 - 3 } Category & Frequency & Percent \\
\hline Retail & 116 & 35.5 \\
Computer/technical products & 51 & 15.6 \\
Food and beverage & 62 & 19 \\
Communications & 37 & 11.3 \\
Auto/motorcycle & 23 & 7 \\
Travel/leisure/sports & 16 & 4.9 \\
Personal care & 12 & 3.7 \\
Bank & 3 & 0.9 \\
Health & 1 & .3 \\
Other & 6 & 1.8 \\
Total & 327 & 100.0 \\
\hline
\end{tabular}

\section{Appendix C The DART Scale (22-items)}

Seven point Likert scale, 1 strongly disagree to $7=$ strongly agree (item dimension in parenthesis)

1. The provider communicates with the customer to receive input on improving the service/product experience. (D)

2. The provider is interested in communicating with the customer about the best ways to design and deliver a quality service/product experience. (D)

3. The provider uses multiple channels of communication to encourage greater exchange of ideas with the customer about the service/product experience. (D)

4. The provider and the customer have active dialogue on how to add value in the service /product experience. (D)

5. The customer is encouraged to communicate with the provider about any and all aspects of the service/product experience. (D)

6. Multiple lines of communications are used by the provider to gather input and ideas from the customer. (D)

7. The provider actively promotes dialogue with the customer to learn more about the customer's reaction to the service/product experience. (D)

8. The customer has many opportunities to share his/her ideas with the provider about adding value to the service/provider experience. (D)
9. The provider makes it easy for the customer to communicate his/her ideas about the design and delivery of the service/product experience. (D)

10. The provider lets the customer decide how he/ she receives the service/product offering. (A)

11. The customer has many options to choose how he/ she experiences the service/product offering. (A)

12. It is easy for the customer to receive the service/ product offering when, where and how he/she wants it. (A)

13. The provider provides the customer with comprehensive information pertaining how risks and benefits were assessed for the service experience or product. (R)

14. The customer receives comprehensive information pertaining to the risks and benefits of the service/product experience. (R)

15. The provider fully informs the customer about all risks stemming from product or service use. (R)

16. The provider provides the customer with necessary tools and support to make fully informed decisions as to whether he or she should participate in the service/product experience. (R)

17. The provider is very clear and factual about both the negative and positive factors associated with the service/ product offering. (R)

18. The provider allows the customer to make informed decisions regarding the risks and benefits of the product /service experience. (R)

19. The provider fully discloses to the customer information which might be helpful to improve the outcomes of the service/ product experience. $(\mathrm{T})$

20. The customer is given open access to information that might be useful in enhancing the overall design and delivery of the service/product experience. ( $\mathrm{T}$ )

21. The customer and provider are treated as equal partners in sharing information that is needed to achieve a successful service/product experience. ( $\mathrm{T}$ )

22. The provider fully discloses the customer detailed information regarding the costs and pricing associated with the design and delivery of the service/ product experience. (T)

\section{Appendix D}

This set of statements involves your relationship with the service provider and how that affects your 
perceptions of the particular service/product experience. In this case, the term "provider" again refers to the company/product you selected and the term "service/product experience" refers to the overall experience.

Service loyalty Scale $(\alpha=0.76)$ Strongly disagree 1 ; Strongly agree 7

1. I get bored with going to the same provider even if the service/ product is good. (reversed)

2. I would get tired of trying the same provider for this service/ product experience. (reversed)

3. A lot of time, I feel the urge to try a new provider for the service/ product offering. (reversed)

4. If I like the service/ product provider, I rarely switch from it just to try a new provider for the same service/product experience.
5. I would prefer going to the same provider, rather than trying a new one from time-to-time.

Shared responsibility Scale $(\alpha=0.78)$ Strongly disagree 1; Strongly agree 7

1. The provider and I work together as equals when it comes to making this service/ product successful.

2. For this service/ product experience to end successfully, both the provider and I must rely on each other.

3. The more control I have over the service/ product experience, the more responsible I feel for the experience success.

4. The provider and I are both accountable for the results of the service/ product experience. 